\title{
The Effect of Age, Weight on Hypertensive Patients in State Hospital, Osogbo, Osun State, Nigeria
}

\author{
Oladimeji O. A. ${ }^{1} \quad$ Ogunbanwo T. S. ${ }^{2} \quad$ Oyewole O. ${ }^{3}$ \\ 1.Department of Statistics, Federal Polytechnic, Ile-Oluji, Ondo State, Nigeria \\ 2.Department of Mathematics and Statistics, Osun State College of Technology, Esa-Oke, Osun State, Nigeria \\ 3.Physical Science Department, Bells University, Ota, Ogun State, Nigeria
}

\begin{abstract}
This project work examines the contribution of age, weight and height to the blood pressure of 50 randomly selected individuals from medical record unit of the State Hospital, Osogbo, Osun state. The fitted mathematical model that represents the relationship among the variables is $\mathrm{Y}=73.222+0.075 \mathrm{X}_{1}-0.044 \mathrm{X}_{2}+12.178 \mathrm{X}_{3}$. This implies that the rate of change in $Y$ (Blood Pressure) due to $\mathrm{X}_{1}$ (age) is 0.075 units, $\mathrm{X}_{2}$ (weight) is -0.044units, $\mathrm{X}_{3}$ (height) is 12.178 units. The estimation regression equation indicates that the mean of Y's are expected to increase by 0.075 when $X_{1}$ increased by one unit holding $X_{2}$ and $X_{3}$ constant, the mean of $Y$ 's are expected to decrease by 0.044 when $\mathrm{X}_{2}$ increased by one unit holding $\mathrm{X}_{1}, \mathrm{X}_{3}$ constant, the mean of $\mathrm{Y}$ 's are expected to increase by 12.178 when $\mathrm{X}_{3}$ increased by one holding $\mathrm{X}_{1}$ and $\mathrm{X}_{2}$ constant. The negative coefficient of $\mathrm{X}_{2}$ indicates that blood pressure decreases as weight increases and vice versa. The F- test was used to examine the adequacy of the fitted model. The F- calculated (0.394) is not large enough for the rejection of the null hypothesis and that implies that the model is significant and adequate for prediction. The Variance Inflation Factor (VIF) and tolerance values computed from the data were examined to determine the presence and severity of multicollinearity. The tolerance values are greater than 0.1 and simultaneously, the Variance Inflation factors are all below 15 which is an indication of no multicollinearity in the data. Based on the findings, people who are becoming taller with respect to age should watch their blood pressure as the blood pressure is found to increase with increase in height and age.
\end{abstract}

DOI: $10.7176 / \mathrm{JHMN} / 95-09$

Publication date: November $30^{\text {th }} 2021$

\section{INTRODUCTION}

Blood pressure, force originating in the pumping action of the heart, exerted by the blood against the walls of the blood vessels; the stretching of the vessels in response to this force and their subsequent contraction are important in maintaining blood flow through the vascular system.

In humans, blood pressure is usually measured indirectly with a special cuff over the brachial artery (in the arm) or the femoral artery (in the leg). There are two pressures measured: (1) the systolic pressure (the higher pressure and the first number recorded), which is the force that blood exerts on the artery walls as the heart contracts to pump the blood to the peripheral organs and tissues, and (2) the diastolic pressure (the lower pressure and the second number recorded), which is residual pressure exerted on the arteries as the heart relaxes between beats. In healthy individuals, systolic pressure is normally between 90 and 120 millimetres of mercury $(\mathrm{mmHg})$. Diastolic pressure is normally between 60 and $80 \mathrm{mmHg}$. Hence, in general, a reading of $110 / 70 \mathrm{mmHg}$ would be considered healthy, whereas $80 / 50 \mathrm{mmHg}$ would be low and $160 / 100 \mathrm{mmHg}$ would be high.

Studies have shown that there are stark contrasts in the blood pressure of vessels of different sizes. For example, blood pressure in the capillaries is usually about 20 to $30 \mathrm{mmHg}$, whereas the pressure in the large veins may become negative (lower than atmospheric pressure $[760 \mathrm{mmHg}$ at sea level]; technically, measurements of blood pressure are relative to atmospheric pressure, which represents the "zero reference point" for blood pressure readings).

Cardiovascular Diseases involve any medical conditions related to the heart and blood vessels and remain the biggest cause of deaths worldwide according to World Health Organization (WHO) report (Iqbal and Ahmad (2016). Hypertension represents a major and correctable cardiovascular risk factor. The right diagnosis of hypertension and accurate assessment of cardiovascular risk are essential to give appropriate treatment to hypertensive patients (Hermida, etal (2013) and Dago, 2017) Public urban and rural opinion in its great majority, in many underdeveloped countries (i.e. Cote d'Ivoire) ignores the bases of public health education vis-à-vis of hypertension troubles prevention (Dago, 2017).

Regardless of years of public health education in developed countries, hypertension awareness remains still problematic, with only a weak proportion with regard of adults and the elderly aware of their hypertension status (Bethany and Anna (2015), Vitale (2010). Several studies evoked gender difference between men and women in hypertension troubles incidence (Bethany and Anna, (2015), Cutler (2008), and Sandberg, etal (2011). While hypertension prevalence is highest in older populations, almost 20 percent of young adults are 
hypertensive (Nguyen, 2011). Henceforth, we believe that hypertensive patient age parameter can be useful to efficiently predict and interpret hypertension gender status in a hypertensive population.

Few studies, however, have examined in the American Journal of Medicine and Medical Sciences 2018, 8(12): 360-367 361 the influence of both age and weight features in discerning gender status differences in hypertension or hypertension awareness among hypertensive population. Further, several surveys showed linear relationship between age and hypertension incidence and as well suggested men having a higher propensity in manifesting hypertension troubles as opposed to women, in primary prevention services (Rosengren, etal (2006) and Strokes, (2009). The most recent recommendations for the management of hypertension were published recently. While there are age-dependent recommendations for blood pressure (BP) goals, the guidelines remain the same irrespective of gender, despite the abundance of evidence supporting sex and gender differences in hypertension (Hermida, etal 2013, James 2014). Although both men and women develop hypertension, distinct gender differences in the incidence and severity of hypertension are well established where males have a higher incidence of hypertension compared to females of the same age until the sixth decade of life (Yoon, 2015, and Mozaffarian, 2016).

Also, obesity predisposes to hypertension and alters the course of hypertensive cardiovascular disease in ways that are only now coming to be appreciated. The strong association of obesity with hypertension and diabetes further complicates the picture in patients with such conditions and complicates the design of effective therapeutic interventions. However difficult to realize, weight loss must be the first line of therapy (Richard, 2009). Obesity increases the risk of the development of hypertension. This relationship has been the subject of several surveys [Frohlich, 2002, Hall, 2002]. Taking together, these studies evoked and suggested overweight feature as favoring and/or as a source of hypertension as well as other metabolism diseases incidence.

Here, we combined both age and weight features because of their well-established involvement explaining hypertension troubles incidence, with the purpose to predict and characterize a hypertensive patient population gender and sex. Several descriptive as well as analytical statistical and Receiver Operating Characteristic (ROC) performance tests [Hajian, 2011, and Dago, 2016] were realized for this purpose considered statistical parameters or variables (hypertensive patient's age and/or weight features).

\section{AIM AND OBJECTIVES OF THE STUDY}

This study is aimed at investigating the effect of Age, Weight on Hypertensive Patients in some selected patients in State Hospital, Osogbo, Osun State.

The objectives of this study are to:

(a) Form a linear model

(b) Test the significance of the $\beta$ 's.

(c) Obtain the pair-wise correlation coefficient, coefficient of determination and multiple correlation coefficients.

(d) Test for conformance of the data to assumptions of multicollinearity.

(e) Obtain the descriptive statistic for the dependent (blood pressures) variable and independent (age, weight) variable.

\section{LITERATURE REVIEW}

Prospective studied have shown that obesity increase the risk of developing hypertension (Friedman et al. 2008, Youg et al, 2008). Weight gain in adult life especially seems to be an important risk factor for the development of hypertension (Friedman et al. 2008, Huag et al, 2008). In a recent updated evaluation of the nurses' health study (Huag et al, 2008). A long term follow up study of more than 80,000 female nurses. BMI at 18 years of age and midlife were positively associated with the occurrence of hypertension long term and medium term weight loss was associated with a reduced risk in the group of women with a high base line BMI.

A central fat distribution is a better is a predictor for hypertension than overall fat mass. Early studied show a good correlation between the waist-to-hip ratios (Lapidus et al, 2008. Laisson et al, 2004) and blood pressures levels. Later studied using computed tomography to measure the exact amount of visceral adipose tissue (Peiris et al. 2009. Kanal et al, 2009) showed strong correlation with systolic and disstolic blood pressure level. Recently waist circumference has been proposed as an indicator of abdominal fat mass and a waist circumference. Above $88 \mathrm{~cm}$ in women and above $102 \mathrm{~cm}$ in men. Has been shown to correlation with blood pressure level both in European (Han et al. 2005) and African population.

In a recent study by Kanai et al.(2009). The change in mean blood pressure after weight reduction was correlation with change in visceral fat area and not with change in body weight of BMI. This suggest that a decrease in intra-abdominal fat reduces blood pressure in obese hypertension patient.

A reduced in body weight can be achieved by a decrease in energy intake and/or an increase in energy expenditure comprehensive weight loss programs include a dietary a behavioral and a physical activity component. Rocchini et al (2008) showed in a group of 72 obese adolescent that a combination of caloric 
restriction, behavior change alone.

In contrast a recent study by Dengel et al, (2008). In which the independent and combined effect of weight loss and acrobic exercise on blood pressure were studied in a group of older men. Combining the two interventions did not reduce blood pressure to a greater degree than the two interventions did independently. An age dependent factor might explain this difference in outcome.

Geller et al. (2009) conducted a study on 227 males of age at least 40 years. Who are with invasive melanoma?

Ito.et al (2007).In their attempt to determine the level of Crythrocyte aidose reductase protein (AR-p) in diabetic patient by a two-site enzyme linked immunosorbent assay. Classified 95 non-insulin-dependent diabetes mellitus (NIDDOM) patient into two groups. Based on the result of seven nerve function tests: group I, without demonstrable neuropathy and group II, with overt neuropathy. Multivariate logistic regression analysis was subsequently used to identify two independent risk factor for overt neuropathy in diabetic patients. Takahashi et al. (2008). In their study to investigate the risk factors for diabetic severe neurophy independent of glycemic control and duration of diabetics. Used logistic regression analysis technique to establish that maximum body mass index (BMI) in the past minus present BMI and the level of erythrocyte aidose reeducates protein together with measurement of erythrocyte AR level may be useful for predicting severe neuropathy in non-insulindependent diabetes mellitus (NIDDM).

Classification of blood pressure for adult aged 18 years and older

\begin{tabular}{|l|l|l|}
\hline Category & Systolic $(\mathrm{mm} \mathrm{Hg})$ & Diastolic $(\mathrm{mm} \mathrm{Hg})$ \\
\hline Optimal & $<120$ & $<80$ \\
\hline Normal & $<130$ & $<85$ \\
\hline High normal & $130-139$ & $85-89$ \\
\hline Hypertension & & \\
\hline Stage 1 & $140-159$ & $90-99$ \\
\hline Stage 2 & $160-179$ & $100-109$ \\
\hline Stage 3 & $\geq 180$ & $\geq 110$ \\
\hline
\end{tabular}

Source joint national committee on prevention. Evaluation and treatment of high blood pressure.

Dauziel et al (2007) recently reported that adults born moderately preterm had increase blood pressures at 30 year of age. Low gestation at birth was the key feature of this association. Whereas birth weight adjusted for gestation age was not. Other studied support this observation. Linking earlier gestation and/or preterm birth with higher blood pressure in adult 14-18 in a large family based study of gestation age intrauterine growth and blood pressure.

Lawlor et al (2007) provide evidence for an inverse association of gestation age with systolic blood pressure at age 17-19 year in both siblings and no sibling. Gestation length has also been linked to raise blood pressure in children. Blood pressure in adulthood is unequivocally positively associated with disease and stroke risk and recent research has suggested that increased pulse pressure defined as the difference between systolic and diastolic blood pressure may also be an important component of increased risk of cardiovascular disease, particularly when observed in conjunction with raised systolic blood pressure (Franklin et al, 2007).

\section{METHODOLOGY}

In order to determine the relationship between blood pressure, age and weight. A linear regression model relating the variable was obtained. The statistics approach to analysis of data involves the use of multiple regression model and determination of multicollinearity among the independent variables

\section{STATISTICAL TOOL USED}

Multiple Linear Regression Parameter;

By matrix notation:

$$
\widehat{\mathrm{Y}}=\beta_{0}+\beta_{1} \mathrm{X}_{1}+\beta_{2} \mathrm{X}_{2}+\mathrm{U}_{\mathrm{i}}
$$

$$
\begin{gathered}
\hat{Y}=X \beta+U_{i} \text {, where } \\
\beta=\left(X^{1} X\right)^{-1} X^{1} Y \\
\text { where }\left(X^{1} X\right)^{-1}=\left[\begin{array}{ccc}
n & \sum X_{1} & \sum X_{2} \\
\sum X_{1} & \sum X_{1}^{2} & \sum X_{1} X_{2} \\
\sum X_{2} & \sum X_{1} X_{2} & \sum X_{2}^{2}
\end{array}\right]^{-1} \\
X^{1} Y=\left[\begin{array}{l}
\beta_{0} \\
\beta_{1} \\
\beta_{2} \\
\beta_{3}
\end{array}\right] \text { and }
\end{gathered}
$$




$$
\beta_{0}=\frac{1}{n}\left(\sum Y-\widehat{\beta_{1}} \sum X_{1}-\widehat{\beta_{2}} \sum X_{2}\right)
$$

Therefore

$\hat{Y}=\hat{\beta}_{0}+\hat{\beta}_{1} \sum X_{1}+\hat{\beta}_{2} \sum X_{2}$ which is the estimate of $\mathrm{Y}$

Computation of simple correlation coefficient

It is also refers to as Pearson correlation coefficient which can be computed as follows:

$$
\mathrm{X}_{\mathrm{ij}}=\frac{\mathrm{n} \sum \mathrm{x}_{\mathrm{i}} \mathrm{x}_{\mathrm{j}}-\sum \mathrm{x}_{\mathrm{i}} \sum \mathrm{x}_{\mathrm{j}}}{\sqrt{\left[\mathrm{n} \sum \mathrm{x}_{\mathrm{i}}^{2}-\left(\sum \mathrm{x}_{\mathrm{i}}\right)^{2}\right]\left[\mathrm{n} \sum \mathrm{x}_{\mathrm{j}}^{2}-\left(\sum \mathrm{x}_{\mathrm{j}}\right)^{2}\right]}} \text { this } \mathrm{X}_{\mathrm{ij}} \text { is for the explanatory variables alone. }
$$

Also;

$$
\mathrm{Y}_{\mathrm{ij}}=\frac{\mathrm{n} \sum \mathrm{X}_{\mathrm{i}} \mathrm{Y}_{\mathrm{j}}-\sum \mathrm{X}_{\mathrm{i}} \sum \mathrm{Y}_{\mathrm{j}}}{\sqrt{\left[\mathrm{n} \sum \mathrm{X}_{\mathrm{i}}^{2}-\left(\sum \mathrm{X}_{\mathrm{i}}\right)^{2}\right]\left[\mathrm{n} \sum \mathrm{Y}_{\mathrm{j}}^{2}-\left(\sum \mathrm{Y}_{\mathrm{j}}\right)^{2}\right]}}
$$

\section{ANALYSIS OF DATA}

\begin{tabular}{|c|c|c|c|c|c|}
\hline $\mathrm{S} / \mathrm{No}$ & SEX & AGE (years) & WEIGHT (kilograms) & HEIGHT (meters) & $\mathrm{BP}(\mathrm{mmHg})$ \\
\hline 1 & $\mathrm{~F}$ & 54 & 56 & 1.67 & $110 / 70$ \\
\hline 2 & $\mathrm{M}$ & 30 & 85 & 1.70 & $133 / 67$ \\
\hline 3 & $\mathrm{M}$ & 48 & 92 & 1.50 & $102 / 88$ \\
\hline 4 & $\mathrm{M}$ & 65 & 70 & 1.65 & $131 / 87$ \\
\hline 5 & $\mathrm{~F}$ & 51 & 85 & 1.67 & $113 / 72$ \\
\hline 6 & $\mathrm{~F}$ & 28 & 50 & 1.58 & $133 / 84$ \\
\hline 7 & $\mathrm{M}$ & 35 & 74 & 1.61 & $109 / 56$ \\
\hline 8 & $\mathrm{~F}$ & 63 & 70 & 1.75 & $152 / 87$ \\
\hline 9 & $\mathrm{M}$ & 39 & 76 & 1.71 & $145 / 100$ \\
\hline 10 & $\mathrm{~F}$ & 35 & 56 & 1.66 & $122 / 76$ \\
\hline 11 & $\mathrm{~F}$ & 65 & 99 & 1.68 & $113 / 67$ \\
\hline 12 & $\mathrm{~F}$ & 32 & 46 & 1.50 & $129 / 85$ \\
\hline 13 & $\mathrm{M}$ & 70 & 48 & 1.54 & $120 / 83$ \\
\hline 14 & $\mathrm{M}$ & 40 & 43 & 1.70 & $120 / 83$ \\
\hline 15 & $\mathrm{~F}$ & 27 & 56 & 1.68 & $129 / 52$ \\
\hline 16 & $\mathrm{M}$ & 31 & 49 & 1.62 & $123 / 83$ \\
\hline 17 & $\mathrm{~F}$ & 45 & 65 & 1.62 & $156 / 83$ \\
\hline 18 & $\mathrm{M}$ & 27 & 56 & 1.68 & $129 / 52$ \\
\hline 19 & $\mathrm{M}$ & 65 & 74 & 1.69 & $152 / 89$ \\
\hline 20 & $\mathrm{~F}$ & 45 & 85 & 1.61 & $140 / 89$ \\
\hline 21 & $\mathrm{M}$ & 38 & 56 & 1.67 & $149 / 72$ \\
\hline 22 & $M$ & 22 & 49 & 1.57 & $127 / 73$ \\
\hline 23 & $\mathrm{~F}$ & 60 & 69 & 1.58 & $123 / 61$ \\
\hline 24 & $\mathrm{~F}$ & 35 & 72 & 1.06 & $133 / 78$ \\
\hline 25 & $\mathrm{M}$ & 20 & 48 & 1.63 & $118 / 69$ \\
\hline 26 & $\mathrm{~F}$ & 27 & 56 & 1.67 & $127 / 85$ \\
\hline 27 & $\mathrm{M}$ & 63 & 70 & 1.75 & $152 / 87$ \\
\hline 28 & $\mathrm{M}$ & 50 & 76 & 1.69 & $181 / 120$ \\
\hline 29 & $\mathrm{~F}$ & 80 & 79 & 1.62 & $135 / 82$ \\
\hline 30 & $\mathrm{~F}$ & 65 & 99 & 1.68 & $113 / 67$ \\
\hline 31 & $\mathrm{M}$ & 72 & 40 & 1.52 & $131 / 73$ \\
\hline 32 & $\mathrm{~F}$ & 38 & 40 & 1.59 & $107 / 76$ \\
\hline 33 & $\mathrm{~F}$ & 35 & 74 & 1.61 & $109 / 56$ \\
\hline 34 & $\mathrm{M}$ & 21 & 50 & 1.61 & $130 / 120$ \\
\hline 35 & $\mathrm{M}$ & 22 & 47 & 1.63 & $132 / 72$ \\
\hline 36 & $\mathrm{~F}$ & 45 & 66 & 1.62 & $116 / 77$ \\
\hline 37 & $\mathrm{~F}$ & 25 & 45 & 1.62 & $116 / 77$ \\
\hline 38 & $\mathrm{M}$ & 32 & 52 & 1.60 & $117 / 64$ \\
\hline 39 & $\mathrm{~F}$ & 50 & 53 & 1.62 & $130 / 80$ \\
\hline 40 & $\mathrm{M}$ & 35 & 60 & 1.75 & $114 / 79$ \\
\hline
\end{tabular}

The table below shows the summary of data on age, weight and height to the blood pressure of 50 randomly selected individuals from medical record unit of the State Hospital, Osogbo, Osun state. 


\begin{tabular}{|c|c|c|c|c|c|}
\hline $\mathrm{S} / \mathrm{No}$ & SEX & AGE (years) & WEIGHT (kilograms) & HEIGHT (meters) & $\mathrm{BP}(\mathrm{mmHg})$ \\
\hline 41 & M & 65 & 65 & 1.70 & $117 / 88$ \\
\hline 42 & $\mathrm{~F}$ & 45 & 54 & 1.50 & $105 / 75$ \\
\hline 43 & $\mathrm{~F}$ & 32 & 62 & 1.52 & $123 / 82$ \\
\hline 44 & $\mathrm{M}$ & 28 & 46 & 1.60 & $112 / 69$ \\
\hline 45 & $\mathrm{~F}$ & 29 & 66 & 1.70 & $102 / 68$ \\
\hline 46 & $\mathrm{M}$ & 26 & 51 & 1.70 & $131 / 90$ \\
\hline 47 & $\mathrm{~F}$ & 22 & 65 & 1.75 & $123 / 80$ \\
\hline 48 & $\mathrm{~F}$ & 50 & 73 & 1.70 & $137 / 74$ \\
\hline 49 & $\mathrm{M}$ & 62 & 68 & 1.73 & $127 / 81$ \\
\hline 50 & $\mathrm{M}$ & 65 & 70 & 1.75 & $137 / 82$ \\
\hline
\end{tabular}

Source: State Hospital Osogbo, Osun State (survey 2020)

Descriptive Statistics

\begin{tabular}{|l|l|l|l|}
\hline & Mean & Std. Deviation & $\mathrm{N}$ \\
\hline mean arterial pressure & 93.5333 & 11.15486 & 50 \\
age of patients & 43.0800 & 16.35055 & 50 \\
weight of patients & 63.1200 & 14.88410 & 50 \\
height of patients & 1.6312 & .10735 & 50 \\
\hline
\end{tabular}

Coefficients for model fitting

\begin{tabular}{|ll|l|l|l|l|l|}
\hline \multirow{2}{*}{ Model } & \multicolumn{2}{|l|}{ Unstandardized Coefficients } & Standardized Coefficients & $\mathrm{t}$ & Sig. \\
\cline { 3 - 5 } & & $\mathrm{B}$ & Std. Error & Beta & & \\
\hline \multirow{2}{*}{1} & (Constant) & 73.222 & 25.034 & & 2.925 & .005 \\
& age of patients & .075 & .111 & .110 & .680 & .500 \\
& weight of patients & -.044 & .122 & -.059 & -.364 & .717 \\
& height of patients & 12.178 & 15.281 & .117 & .797 & .430 \\
\hline
\end{tabular}

\begin{tabular}{|ll|l|l|l|l|l|}
\hline \multicolumn{2}{|c|}{ MNOdel $^{2}$} & Sum of Squares & Df & Mean Square & F & Sig. \\
\hline \multirow{3}{*}{1} & Regression & 152.695 & 3 & 50.898 & .394 & $.758^{\mathrm{b}}$ \\
& Residual & 5944.416 & 46 & 129.226 & & \\
& Total & 6097.111 & 49 & & & \\
\hline
\end{tabular}

a. Dependent Variable: mean arterial pressure

b. Predictors: (Constant), height of patients, age of patients, weight of patients Coefficient of determination and multiple correlations.

\begin{tabular}{|l|l|l|l|l|}
\hline Model & R & R Square & Adjusted R Square & Std. Error of the Estimate \\
\hline 1 & $.158^{\mathrm{a}}$ & .025 & -.039 & 11.36778 \\
\hline
\end{tabular}

a. Predictors: (Constant), height of patients, age of patients, weight of patients

b. Dependent Variable: mean arterial pressure

Collinearity statistics

\begin{tabular}{|ll|l|l|}
\hline \multirow{2}{*}{ Model } & \multicolumn{2}{|l|}{ Collinearity Statistics } \\
\cline { 3 - 4 } & & Tolerance & VIF \\
\hline \multirow{2}{*}{1} & & \\
& (Constant) & .804 & 1.244 \\
& age of patients & .803 & 1.246 \\
& weight of patients & .980 & 1.020 \\
\hline
\end{tabular}

\section{Correlations}

\begin{tabular}{|ll|l|l|l|l|}
\hline & & $\begin{array}{l}\text { mean arterial } \\
\text { pressure }\end{array}$ & $\begin{array}{l}\text { age of } \\
\text { patients }\end{array}$ & $\begin{array}{l}\text { weight of } \\
\text { patients }\end{array}$ & $\begin{array}{l}\text { height of } \\
\text { patients }\end{array}$ \\
\hline \multirow{3}{*}{ Pearson Correlation } & mean arterial pressure & 1.000 & .098 & .004 & .123 \\
& age of patients & .098 & 1.000 & .438 & .117 \\
& weight of patients & .004 & .438 & 1.000 & .123 \\
& height of patients & .123 & .117 & .123 & 1.000 \\
\hline
\end{tabular}




\section{SUMMARY OF FINDINGS}

This project work examines the contribution of age, weight and height to the blood pressure of 50 randomly selected individuals from medical record unit of the State Hospital, Osogbo, Osun state. The fitted mathematical model that represents the relationship among the variables is $\widehat{Y}=73.222+0.075 \mathrm{X}_{1}-0.044 \mathrm{X}_{2}+12.178 \mathrm{X}_{3}$. This implies that the rate of change in $\mathrm{Y}$ (Blood Pressure) due to $\mathrm{X}_{1}$ (age) is 0.075 units, $\mathrm{X}_{2}$ (weight) is -0.044 units, $\mathrm{X}_{3}$ (height) is 12.178 units. The estimation regression equation indicates that the mean of $\mathrm{Y}$ 's are expected to increase by 0.075 when $\mathrm{X}_{1}$ increased by one unit holding $\mathrm{X}_{2}$ and $\mathrm{X}_{3}$ constant, the mean of $\mathrm{Y}$ 's are expected to decrease by 0.044 when $X_{2}$ increased by one unit holding $X_{1}, X_{3}$ constant, the mean of $Y^{\prime}$ 's are expected to increase by 12.178 when $\mathrm{X}_{3}$ increased by one holding $\mathrm{X}_{1}$ and $\mathrm{X}_{2}$ constant. The negative coefficient of $\mathrm{X}_{2}$ indicates that blood pressure decreases as weight increases and vice versa. The F- test was used to examine the adequacy of the fitted model. The F- calculated (0.394) is not large enough for the rejection of the null hypothesis and that implies that the model is significant and adequate for prediction.

The Variance Inflation Factor (VIF) and tolerance values computed from the data were examined to determine the presence and severity of multicollinearity. The tolerance values are greater than 0.1 and simultaneously, the Variance Inflation factors are all below 15 which is an indication of no multicollinearity in the data.

\section{CONCLUSION}

This paper has modeled blood pressure as a function of age, weight, and height. The model revealed positive relationship between blood pressure and age which indicates increase in age leads to increase blood pressure, inverse relationship between blood pressure and weight indicates increase in weight leads to decrease in blood pressure and positive relationship between blood pressure and height indicates increase in height leads to increase in blood pressure.

The independent variables considered: age, weight, and height do not determine the blood pressure of the fifty (50) randomly selected individuals since the estimate of the correlation coefficient shows a weak relationship between the dependent and the independent variables. Also, the test of collinearity shows there is no collinearity among the independent variables.

\section{REFERENCES}

Bethany E, Anna Z. (2015): Gender Differences in Hypertension and Hypertension Awareness among Young Adults Biodemography Soc Biol. 61 (1): 1-17.

Cutler JA, Sorlie PD, Wolz M, Thom T, Fields LE, Roccella EJ (2008): Trends in hypertension prevalence, awareness, treatment, and control rates in United States adults between 1988- 1994 and 1999-2004. Hypertension. 52 (5): 818-827.

Dalziel SR,Parag V, Rodegers A, Harding JE. (2007): Cardovascular risk factors at age 30 following preterm birth. Int J Epidemiol; 36: 907-915.

Dengel DR, Galecki AT, Hagberg JM, Pratley RE. (2008): The independent and combined effects of weight loss and aerobic exercise on blood pressure and oral glucose tolerance in older men. Am J Hypertens.; 11:1405$12,7$.

Dago ND, Diarrassouba N, (2017): Performance Assessment of the Recurrence of Cardiovascular Pathologies Symptoms in a Hypertensive Population. Journal of Health Science 7 (1): 9- 19.

Friedman GD, Selby JV, Quesenberry CP, Armstrong MA. Klatsky AL, (2008): Precursors of essential hypertension. Prev Med.; 17:387-402.

Frohlich ED (2002): Clinical management of the obese hypertensive patient. Cardiol Rev. 10 (3): 127-138.

Geller AC, Johnson MD. Miller DR. Brooks, K.R. Layton C.J. Susan, M. et al (2009). Factor associated with physical discovery carly melanoma in middle-aged and older men. Arch Dermatol, 145(4), 409-414.

Hajian Tilaki KO, Hanley JA, Nassiri V (2011): An extension of parametric ROC analysis for calculating diagnostic accuracy when the underlying distributions are mixture of Gausian. J App Stat. 38:2009-22

Hall JE, Crook ED, Jones DW, Wofford MR, Dubbert PM (2002): Mechanisms of obesity- associated cardiovascular and renal disease. Am J Med Sci. 324 (3):127-137.

Harris K, Whitsel EA (2011): Discordance in national estimates of hypertension among young adults. Epidemiology. 22(4):532-541.

Hermida RC, Ayala DE, Mojon A, Fontao MJ, Chayan L, Fernandez JR (2013): Differences between men and women in ambulatory blood pressure thresholds for diagnosis of hypertension based on cardiovascular outcomes. Chronobiol Int. 30:221-232.

Huag Z, Willett WC and manson J.E (2008): Body weight, weight change and risk for hypertension in women. Ann intern Med: 128:81-8.

Iqbal D, Ahmad N. (2016): Cardiovascular Diseases and its Treatment. SM J Pharmac Ther. 2 (1): 1009.

Ito MJ, Grobbee DE, peeter PH, Bots Mt. (2005): Average blood pressure and cardiovascular disease related 
mortality in middle aged women. Am .1 Hypertens; 18: 197-201.

James PA, Oparil S, Carter BL, Ortiz E. (2014): Evidence-based guideline for the management of high blood pressure in adults: Report from the panel members appointed to the eighth Joint National Committee (JNC 8). JAMA. 311:507-520.

Kanai H. Tokunaga K. (2009): Decrease in intra-abdominal visceral fat may reduce blood pressure in obese hypertensive women. 27:125-9.

Lapidus L. Bengtsson C. (2008): Distribution of adipose tissue and risk of cardiovascular death: a 12 year follow up of participants in the population study of women in Gothenburg Sweden. Br med j., 289:1257-61.

Larsson B. Sva" Rdudd k. (2004): Abdominal adipose tissue and risk of cardiovascular disease and death: 13 year follow up of participants in the study of men born in 1913. Br Med J 2004; 288:1401-4.

Lawlor DA, Hubinette A. (2007): Associations of gestation age and intrauterine growth with systolic blood pressure in a family based study of 386,485 men in 331,089 families. 115: 562-568.

Mozaffarian D, Benjamin EJ, Go AS, et al (2016): Heart disease and stroke statistics-2016 update: A report from the American Heart Association. Circulation. 133:e38-e360.

Nguyen QC, Tabor JW, etal (2006): Age, clinical presentation and outcome of acute coronary syndromes in the Euroheart acute coronary syndrome survey. Euro Heart J. 27:789- 795.

Peiris AN, Sothmann MS. (2009): Fat distribution and cardiovascular risk. Ann interm Med. 110:867-72

Richard NR (2009): Obesity-Related Hypertension. The Ochsner Journal 9:133-136.

Rocchini AP. Katch V. Anderson J,et al. (2008):blood pressure in obese adolescents, effect of weight loss pediatrics:82:16-23.

Sandberg K, Ji H (2012): Sex differences in primary hypertension. Biol Sex Differ. 3 (1):7.

Strokes GS (2009). Management of hypertension in the elderly patient. Clinical Intervention in Aging. 4: 379389.

Takahashi Y, (2008). Erythrocyte aldose reductase protein a clue to elucidate risk factor for diabetic neuropathics independent of glycemic control. Diabetic research and clinical practice 42(2), 101-107.

Vitale C, Fini M, Speziale G, Chierchia S (2010): Gender differences in the cardiovascular effects of sex hormones. Fundam Clin Pharmacol. 24 (6): 675-685.

Yoon SS, Gu Q, Nwankwo T, Wright JD, Hong Y, Burt V (2015). Trends in blood pressure among adults with hypertension: United States, 2003 to 2012. Hypertension. 65:54-61. 